\title{
Distribuição das subpopulações de linfócitos B e T sanguíneos em bovinos leiteiros infectados pelo vírus da leucemia bovina
}

José Augusto Ferronatto[a, $]^{[}$, Maiara Garcia Blagitz ${ }^{[b]}$, Fernando Nogueira de Souza ${ }^{[b]}$, Camila Freitas Batista ${ }^{[b]}$, Luis Fernando Fernandes Azevedo ${ }^{[b]}$, Alice Maria Melville Paiva Della Libera ${ }^{[b]}$

\footnotetext{
[a] Universidade do Oeste de Santa Catarina (UNOESC), Xanxerê, SC, Brasil

[b] Veterinary Clinical Immunology Research Group, Departamento de Clínica Médica, Faculdade de Medicina Veterinária e Zootecnia, Universidade de São Paulo (USP), São Paulo, Brasil
}

${ }^{*}$ Autor correspondente

e-mail: jose_augustoferronatto@hotmail.com

\section{Resumo}

O vírus da leucemia bovina (VLB) é um dos patógenos mais prevalentes dos bovinos, principalmente em rebanhos leiteiros. O VLB apresenta tropismo pelos linfócitos B, acomete os órgãos linfopoiéticos e está associada ao desenvolvimento da linfocitose persistente (LP) e linfossarcoma. 0 presente estudo objetivou avaliar a distribuição das subpopulações de linfócitos B e T sanguíneos de bovinos leiteiros infectados pelo VLB com e sem LP. Para isto, o presente estudo utilizou 25 vacas Holandesas em lactação, que foram separadas em três grupos: 1 - vacas não infectadas pelo VLB (resultados negativos nos testes de imunodifusão em ágar gel e ELISA para o antígeno gp51 do VLB) e sem alterações hematológicas ( $n=9$ ); 2 - vacas infectadas pelo VLB (resultados positivos nos testes de imunodifusão em ágar gel e ELISA para o antígeno gp51 do VLB) e sem alterações hematológicas [alinfocitóticos (AL), $n=10$ ]; 3 - vacas infectadas pelo VLB com LP $(n=6)$. Os bovinos infectados pelo VLB foram classificados com LP quando tiveram contagens de linfócitos $>1,0 \times$ $10^{4} \mu \mathrm{L}^{-1}$ e contagens total de leucócitos $>1,5 \times 10^{4} \mu \mathrm{L}^{-1}$. Após 110 dias da primeira amostragem, foram feitas novas coletas para confirmar a LP, além da coleta de amostras de sangue para análise de citometria de fluxo. A quantificação das subpopulações de linfócitos B (CD21, CD11b e CD5) e T (CD3, CD4 e CD8; e CD3, CD4 e CD25) foi determinada por citometria de fluxo, utilizando anticorpos monoclonais, e a viabilidade dos linfócitos B foi avaliada empregando a anexina-V FITC e o iodeto de propídeo. No presente estudo, observouse aumento acentuado na percentagem e no número absoluto de linfócitos B circulantes (48,15 \pm 5,05\%; $\left.11,50 \pm 1,1910^{3} \mu \mathrm{L}^{-1}\right)$, principalmente linfócitos B CD5 ${ }^{+} \mathrm{CD}_{11 \mathrm{~b}^{+}}\left(41,87 \pm 4,40 \% ; 10,02 \pm 1,04 \mu \mathrm{L}^{-1}\right)$, nos animais infectados pelo VLB com LP, diferente dos animais sadios não infectados pelo VLB (Linfócitos B: 20,73

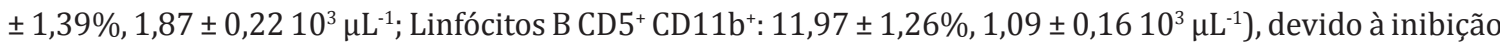


da apoptose. Além disto, o número absoluto de linfócitos $\mathrm{T}\left(\mathrm{CD}^{+}\right)$e o número absoluto e a percentagem e linfócitos T CD4+ CD25 foi maior nos animais infectados pelo VLB com LP $\left(2.42 \pm 0.22 \%, 0.57 \pm 0.0410^{3} \mu \mathrm{L}^{-1}\right)$ do que nos animais sadios não infectados pelo $\operatorname{VLB}\left(1.38 \pm 0.37 \%, 0.12 \pm 0.0310^{3} \mu \mathrm{L}^{-1}\right)$, embora tenha sido observada redução na percentagem de células T. Com base nesses dados, este estudo fornece novas ideias sobre as implicações das infecções VLB para bovinos, destacando a importância de controlar as infecções VLB por causa de seus efeitos indiretos insidiosos, como a maior suscetibilidade de vacas infectadas com VLB, particularmente em vacas VLB infectadas com PL, a novas enfermidades. 